\title{
ANÁLISIS DE LA JURISPRUDENCIA SOBRE LAS COMUNICACIONES PREVIAS Y DECLARACIONES RESPONSABLES DE ACTIVIDADES COMERCIALES O DE SERVICIOS
}

\author{
SONIA GAVIEIRO GONZÁLEZ' \\ Ayuntamiento de Santurtzi \\ sogavie@gmail.com
}

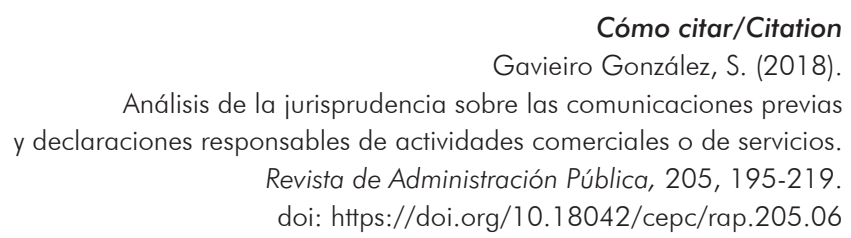

Resumen

Tras la aprobación de la Directiva 2006/123/CE y de las diversas leyes estatales de adaptación a la primera, se ha hecho habitual en el panorama municipal la presentación de comunicaciones/declaraciones responsables para permitir la realización de obras de acondicionamiento de actividades comerciales o de servicios y su consiguiente apertura.

Por ello, se está creando una jurisprudencia que conviene analizar para despejar algunas oscuridades en relación con los efectos de la presentación de estos documentos, con la tramitación a seguir y con la posibilidad de exigir tributos. Incluimos también referencias a la reciente Sentencia del Tribunal Constitucional 91/2017, de 6 de julio de 2017, en relación con diversos preceptos de la Ley de Economía Sostenible.

\section{Palabras clave}

Comunicación; declaración responsable; tributo; jurisprudencia.

1 Doctoranda de la UPV/EHU. 


\section{Abstract}

After the approval of the 2006/123/CE Directive and their corresponding member states laws, it has become common practice in the city councils to receive communications/declaration responsables to allow the realization of works of conditioning commercial activities or services.

For this reason, a jurisprudence is being created that should be analyzed to clear some obscurities in relation to the effects of the presentation of these documents, with the procedure to be followed and with the possibility of demanding taxes. We also include references to the recent sentence of the Constitutional Court No. 91/2017 of July 6, 2017, in relation to various articles of the Law of Sustainable Economy.

\section{Keywords}

Communication; declaration responsible; tax; jurisprudence. 


\section{SUMARIO}

I. INTRODUCCIÓN. II. BREVE ANÁLISIS NORMATIVO. III. TRAMITACIÓN Y EFECTOS DE LAS DECLARACIONES RESPONSABLES Y DE LAS COMUNICACIONES DE ACTIVIDADES COMERCIALES O DE SERVICIO: ESPECIAL ANÁLISIS DE LA JURISPRUDENCIA MÁS RECIENTE: 1. ¿̇La presentación de una declaración responsable o de una comunicación vinculada a una actividad comercial o de servicio conlleva una tramitación? Efectos de su presentación. 2. Posibilidad de exigencia de tributos ante la presentación de una declaración responsable o de una comunicación vinculada a una actividad comercial o de servicio: 2.1. Posibilidad de imposición de una tasa por servicios urbanísticos ante la presentación de una comunicación/declaración responsable vinculada a una actividad comercial o de servicios. 2.2. Posibilidad de exigencia del ICIO ante la presentación de una comunicación/declaración responsable relativa a una obra vinculada a una actividad comercial o de servicios. IV. CONCLUSIÓN.

\section{INTRODUCCIÓN}

Hoy en día nos encontramos inmersos en la crisis de las clásicas categorías cerradas relativas a la actividad de la Administración pública. Una vez superada la teoría de Jordana de Pozas², se pasó a hablar de los siguientes tres tipos de actividad administrativa: el fomento, el servicio público y el control ${ }^{3}$. $\mathrm{Si}$ en el primero tenemos el impulso de una actuación (normalmente, por medio de ayudas), y en el segundo, el ofrecimiento concreto de un servicio a los administrados (habitualmente, a través de una prestación inmaterial que se prolonga en el tiempo), en el tercero de los casos nos encontramos con

2 L. Jordana de Pozas (1949), «Ensayo de una teoría del fomento en el Derecho Administrativo", Revista de Estudios Políticos, 14, págs. $41-54$ (pág. 42).

3 Véase, a modo de ejemplo, I. González Ríos (2014), "Formas de la actividad administrativa», en M. A. Recuerda Girela y C. Agoués Mendizábal (coords.), Lecciones de derecho administrativo con ejemplos (págs. 253-274), Madrid: Tecnos. Esta autora defiende el uso del término de organización y control, en lugar del anterior de actividad de policía. 
cualquier forma de actividad organizativa o controladora (a través de licencias, concesiones, inspecciones, etc.).

Sin embargo, hemos adelantado que la dinámica de la realidad nos lleva hoy a superar esta clasificación puesto que en ella no caben todas las fórmulas o técnicas actuales, ni toda la actividad administrativa, según parte de la doctrina ${ }^{4}$; de hecho, a modo de ejemplo, se citan en este punto las actuaciones sujetas a un control administrativo a posteriori, como las que analizaremos en el presente artículo. Nos estamos refiriendo, en concreto, a las declaraciones responsables y a las comunicaciones (llamadas antes ${ }^{5}$ "previas", pero cuyo adjetivo han perdido con la Ley 39/2015, de 1 de octubre, de Procedimiento Administrativo Común de las Administraciones Públicas —en adelante, LPACAP - ).

A pesar de su cita, esta última teoría no parece ser respaldada por el Tribunal Superior de Justicia (TSJ) de Andalucía de Granada, puesto que este órgano judicial ha calificado recientemente, como mecanismo ordinario de intervención de la Administración en una actividad, «la comunicación previa y declaración responsable conforme» al art. 84 de la Ley 7/1985, de 2 de abril, Reguladora de Bases del Régimen Local (LRBRL) ${ }^{7}$, "tras modificación operada en la misma por la Ley 25/2009", de 22 de diciembre, de modificación de diversas leyes para su adaptación a la Ley sobre el libre acceso a las actividades de servicios y su ejercicio (siendo esta última coletilla relativa a la modificación, añadida por la Sentencia de la Sala de Contencioso-Administrativo del TSJ del Principado de Asturias de 23 de febrero de $2015^{8}$ ). Más en concreto, y siguiendo con la contextualización de este artículo, nos referiremos aquí a las relativas a actividades comerciales o de servicio, por ser las más habituales.

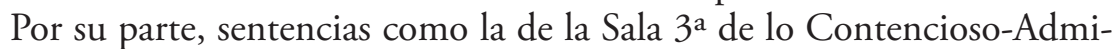
nistrativo, Sección 2a del Tribunal Supremo, 1.558/2016, de 28 de junio de

4 A ese respecto, podemos destacar a J. Esteve Pardo (2012), Lecciones de Derecho administrativo, Madrid: Marcial Pons (págs. 350-351).

5 Es el caso del art. 71 bis ańadido a la Ley 30/1992, de 26 de noviembre, de Régimen Jurídico de las Administraciones Públicas y Procedimiento Administrativo Común, por parte de la Ley 25/2009, de 22 de diciembre, de modificación de diversas leyes para su adaptación a la Ley sobre el libre acceso a las actividades de servicios y su ejercicio.

6 En concreto, hoy el art. 69 de la LPACAP se refiere a declaraciones responsables y a comunicaciones.

7 Se trata de la Sentencia de la Sala de lo Contencioso-Administrativo del TSJ de Andalucía de Granada de 15 de febrero de 2016, fundamento jurídico (FJ) 2º.

8 Léase, en concreto, el fundamento jurídico $3^{\circ}$ de la Sentencia de la Sala de Contencioso-Administrativo del TSJ del Principado de Asturias de 23 de febrero de 2015. 
2016, parecen no tomar partido en el debate relativo a la clasificación de la actividad administrativa y se refieren a estas declaraciones responsables y comunicaciones como figuras sustitutas de la exigencia de licencias, tras relacionar el art. 3 con el 4 de la Ley 12/2012 de Medidas Urgentes de Liberalización del Comercio y Determinados Servicios (LMULCDS). Incluso, en el mismo FJ $3^{\circ}$, concreta que ambas deben contener «una manifestación explícita del cumplimiento de aquellos requisitos que resulten exigibles de acuerdo con la normativa vigente, incluido, en su caso, estar en posesión de la documentación que así lo acredite y del proyecto cuando corresponda», proyecto que vendrá suscrito por técnico/a competente?.

Por último, antes de continuar, debemos dejar claro que no analizaremos en el presente artículo otras figuras reconocidas en algunas normas autonómicas, como es el caso del art. 172.2 de la Ley 7/2002 de Ordenación Urbanística de Andalucía que, como destaca la sentencia de la Sala de lo ContenciosoAdministrativo del TSJ de Andalucía de Málaga de 15 de febrero de 2016, exigen comunicar previamente con una antelación de, al menos diez días, la realización de una obra o uso que está amparado en una licencia urbanística ya obtenida ${ }^{10}$.

\section{BREVE ANÁLISIS NORMATIVO}

Como indica el propio tenor de este epígrafe, vamos a realizar aquí un somero análisis de la normativa relativa a las declaraciones responsables y comunicaciones que se presentan con motivo de obras o del ejercicio de actividades comerciales o de servicios ${ }^{11}$. Sabemos que ambas provienen de la

9 Llegados a este punto, debo recomendar la lectura de la sentencia de la Sala $3^{\text {a }}$ de lo Contencioso-Administrativo, Sección 2a, del Tribunal Supremo no 1.558/2016, de 28 de junio de 2016, en su FJ $3^{\circ}$, no solo por citar las normas estatales de transposición de la Directiva Bolkestein, sino por realizar una auténtica clase magistral definiendo e intentando diferenciar la declaración responsable y la comunicación.

10 Veáse la Sentencia de la Sala de lo Contencioso-Administrativo del TSJ de Andalucía de Málaga de 15 de febrero de 2016, fundamento jurídico $2^{\circ}$.

11 Entre los artículos más recientes leídos al respecto recomendamos los tres siguientes: L. Cosculluela Montaner (2016), «El impacto del Derecho de la UE en la regulación española de la intervención administrativa en la actividad económica", Revista de Administración Pública, 200, págs. 103-120; A. Pena Dorado (2016), «El urbanismo como forma de intervención administrativa. Especial referencia al caso gallego con la Ley 9/2013», Cadernos de Dereito Actual, 4, págs. 119-129; y A. Garrido Juncal (2016), "Las transformaciones del régimen de intervención administrativa en el 
Directiva 123/2006/CE, propuesta por el comisario europeo para el mercado interno Frits Bolkestein. Siguiendo el principio de confianza propio de los países nórdicos (distinto del de control previo existente en países como el nuestro) y el criterio del "reconocimiento único» ${ }^{12}$ adoptado por el Tribunal de Justicia de Luxemburgo en los años ochenta, esta directiva entró en vigor el 28 de diciembre de 2006. Si bien en su art. 2.3 se reconoce que «no se aplicará a la fiscalidad» (una de las cuestiones que vamos a tratar en este artículo), sí se destaca que busca:

[...] facilitar el ejercicio de la libertad de establecimiento de los prestadores de servicios y la libre circulación de estos últimos, manteniendo al mismo tiempo un elevado nivel de calidad en los mismos (art. 1.1), mediante, entre otros instrumentos, la simplificación de los procedimientos administrativos (art. 5.1 y considerando 43). A este fin se somete el régimen de autorización previa a determinados condicionantes $y$, en particular, al de que el objetivo perseguido con la misma no pueda conseguirse mediante una medida menos restrictiva, como un control a posteriori (art. 9) ${ }^{13}$.

En concreto, en lo que respecta a las actividades comerciales o de servicios, podemos destacar brevemente que esta directiva ha sido transpuesta por el Estado de forma bastante general mediante la Ley 17/2009, de 23 de noviembre, sobre el libre acceso a las actividades de servicios y su ejercicio y la Ley 25/2009, de 22 de diciembre, de modificación de diversas leyes para su adaptación a la Ley sobre el libre acceso a las actividades de servicios y su ejercicio. Según reconoce la Sentencia del Juzgado de lo ContenciosoAdministrativo n. ${ }^{\circ} 6$ de Valencia de 27 de abril de 2016, en su FJ $1^{\circ}$, el fin de estas dos normas legales es impulsar la mejora de la regulación del sector servicios, reduciendo trabas injustificadas o desproporcionadas, simplificando los procedimientos y sin olvidar la calidad en los servicios. Por ello, no se podría exigir una autorización previa salvo que se motive suficientemente la inexistencia de discriminación, la proporcionalidad en su exigencia y la necesidad de ese régimen (esta última entendida como justificación por razones de orden público, salud pública, protección del medio ambiente....),

procedimiento de evaluación de incidencia ambiental de actividades. El supuesto particular de la legislación gallega», Revista Catalana de Dret Ambiental, VII, págs. 1-28.

12 Según este principio, los Estados miembros deberán tener la suficiente confianza entre ellos para considerar que las mercancías están «legalmente fabricadas y comercializadas en origen» $y$, de esta manera, debe permitirse su circulación en el mercado interior sin duplicidad de controles.

13 Nos hemos referido aquí a la Sentencia de la Sala $3^{\text {a }}$ de lo Contencioso-Administrativo, Sección 2a, del Tribunal Supremo no 1.558/2016, de 28 de junio de 2016, FJ $3^{\circ}$. 
siendo imprescindible cumplir siempre los principios del art. 9 de la citada Ley 17/2009: justificación por razón imperiosa de interés general, ser objetivos, ser hechos públicos con antelación o ser transparentes y accesibles, entre otros.

Además, deben destacarse también el Real Decreto 2009/2009, de 23 de diciembre, por el que se modifica el reglamento de servicios de las corporaciones locales (concretamente, sus arts. 8 y 15.2), el Real Decreto Ley 8/2011 de medidas de apoyo a los deudores hipotecarios, de control del gasto público y cancelación de deudas con empresas y autónomos contraídas por las entidades locales, de fomento de la actividad empresarial e impulso de la rehabilitación y de simplificación administrativa, así como el artículo 41.1 de la Ley 2/2011, de 4 de marzo, de Economía Sostenible (la cual añade un nuevo artículo 84.bis a la LRBRL, en el sentido de no requerir con carácter general licencia o un control preventivo para el ejercicio de actividades, si bien sí permite dicha posibilidad), precepto confirmado por la STC 91/2017, de 6 de julio, en su FJ 7o y, especialmente hoy, la Ley 12/2012, de 26 de diciembre, de medidas urgentes de liberalización del comercio y de determinados servicios. Todo ello sin olvidar, respecto al ámbito tributario ante la presentación de una comunicación/declaración responsable, la Ley 2/2015, de 30 de marzo, de desindexación de la economía española, puesto que modificó el art. 25 del Real Decreto Legislativo 2/2004, de 5 de marzo, por el que se aprueba el Texto Refundido de la Ley reguladora de las haciendas locales, recordando la necesidad de informes técnico-económicos previos a la imposición de esas tasas concretas, tal y como destacaremos en el apartado correspondiente del presente artículo ${ }^{14}$.

Por su parte, también prácticamente todas las comunidades y ciudades autónomas, así como muchos ayuntamientos han transpuesto la Directiva Bolkestein, bien mediante normas específicas, bien mediante normas al estilo de la ómnibus (aprobando una ley de modificación de todas las leyes autonómicas que precisan adaptarse a la directiva citada), si bien no entraremos en ello para evitar alargarnos en demasía.

14 En concreto, la actual redacción del art. 25 del TRLHL establece que: «Los acuerdos de establecimiento de tasas por la utilización privativa o el aprovechamiento especial del dominio público, o para financiar total o parcialmente los nuevos servicios, deberán adoptarse a la vista de informes técnico-económicos en los que se ponga de manifiesto el valor de mercado o la previsible cobertura del coste de aquellos, respectivamente. Dicho informe se incorporará al expediente para la adopción del correspondiente acuerdo». 


\section{TRAMITACIÓN Y EFECTOS DE LAS DECLARACIONES RESPONSABLES Y DE LAS COMUNICACIONES DE ACTIVIDADES COMERCIALES O DE SERVICIO: ESPECIAL ANÁLISIS DE LA JURISPRUDENCIA MÁS RECIENTE}

\section{1. ¿̇LA PRESENTACIÓN DE UNA DECLARACIÓN RESPONSABLE O DE UNA COMUNICACIÓN VINCULADA A UNA ACTIVIDAD COMERCIAL O DE SERVICIO CONLLEVA UNA TRAMITACIÓN? EFECTOS DE SU PRESENTACIÓN}

Como punto previo en estos momentos, debemos aclarar que toda obra prevista en un proyecto de urbanización, objeto de sus respectivos análisis y aprobaciones municipales, exigirá únicamente tramitar la actividad, si la hubiera. Este sería el caso de los centros de transformación, tal y como recientemente ha reconocido el Juzgado de lo Contencioso-Administrativo $n^{\circ} 1$ de Bilbao, en sentencia de 13 de julio de 2016, de acuerdo con cuyo FJ 2º únicamente se eximiría al mismo de obtener licencia de obras, pero no del cumplimiento de las normas relativas a la actividad y la tramitación de la misma.

Por lo demás, cualquier obra normal de acondicionamiento de una actividad comercial o de servicios sigue, con carácter general, las reglas del Título I de la Ley 12/2012, de 26 de diciembre, de Medidas Urgentes de Liberalización del Comercio y de Determinados Servicios (LMULCDS), siempre que sea de las previstas en el Anexo de la misma ley, que la superficie útil de exposición y venta al público de ese establecimiento permanente no sea superior a $750 \mathrm{~m}^{2}$ y que no tenga impacto en el patrimonio histórico-artístico, ni en el uso privativo y ocupación de los bienes de dominio público ${ }^{15}$. Así, se exigirá licencia de obras cuando, por su sustancialidad, requieran de la redacción de un proyecto de obra, en los términos del art. 2.2 de la Ley 38/1999 de Ordenación de la Edificación; en este sentido, la sentencia del Juzgado de lo Contencioso-Administrativo no 2 de Tarragona de 16 de marzo de 2015 equipara a este supuesto la instalación de una estación radioeléctrica de radioaficionado ${ }^{16}$.

15 A esta conclusión se llega relacionando el art. 2 con el Anexo de la LMULCDS, siempre y cuando la correspondiente comunidad autónoma no haya ampliado el umbral de superficie y/o el catálogo de actividades comerciales o de servicios gracias a la habilitación a ese respecto por parte de la disposición final décima de la misma LMULCDS.

16 Así lo vemos en el fundamento jurídico $5^{\circ}$ de la Sentencia del Juzgado de lo Contencioso-Administrativo n. 2 de Tarragona de 16 de marzo de 2015, la cual considera que la obra de instalación de una estación radioeléctrica de radioaficionado es un acto sujeto a licencia, considerándola incluida en los supuestos del art. 187.2. del Decreto 
Para el resto de obras relacionadas con una actividad comercial o de servicios será suficiente con la presentación de comunicación/declaración responsable relativa al inicio de las mismas, siguiendo los arts. 3.3 y 4 de la LMULCDS citada, tal y como también recuerda la antedicha resolución judicial, en el mismo FJ $5^{\circ}$.

Por su parte, para el inicio de esa actividad bastará con la presentación de comunicación/declaración responsable relativa al ejercicio de la misma, de conformidad con los arts. 3.1 y 4 de la LMULCDS. No puede evitarse en este punto realizar una crítica a la mencionada ley por sujetar al mismo régimen a todas las estaciones o instalaciones radioeléctricas con una superficie que no sea superior a $300 \mathrm{~m}^{2}$, dentro de las cuales se incluyen las estaciones base de telefonía móvil, puesto que no parecen ser el tipo de actividades inocuas o sencillas del tipo de las recogidas en el Anexo de la LMULCDS ${ }^{17}$.

Una vez realizadas las precisiones anteriores, nos centraremos en el contenido de este epígrafe. En concreto, debemos comenzar indicando que esa comunicación/declaración responsable debe ser presentada tanto por el sujeto privado que vaya a realizar esa obra o actividad como por la Administración pública que tenga el mismo objetivo; a modo de ejemplo, este último sería el supuesto de un centro de día municipal. Llegamos a esta conclusión utilizando el razonamiento de la sentencia de la Audiencia Nacional de 1 de septiembre de $2011^{18}$, la cual, realmente, se refiere a una red wifi cuya declaración responsable debe presentarse ante el registro de operadores por explotación de la misma, con base en el art. 6.2 de la Ley 32/2003 de Telecomunicaciones (hoy, art. 6.2 de la Ley 9/2014 del mismo nombre).

Legislativo 1/2010, de 3 de agosto, por el que se aprueba el texto refundido de la Ley de Urbanismo; de manera que, para llegar a dicha conclusión, se basa en los arts. 3 y 4 de la LMULCDS, así como en la disposición transitoria séptima y en la adicional decimonovena de la Ley 9/2014 de Telecomunicaciones.

17 Sin entrar a fondo en esta cuestión, en relación con la posible potencia y los posibles riesgos de exposición a radiación por radiofrecuencia, claramente observamos que una estación base de telefonía, cuyo objetivo es emitir y recibir señales de telefonía móvil, no parece ser una actividad comercial o del sector terciario como las que se citan en el Anexo de la LMULCDS, relativo a tiendas de ropa, oficinas... puesto que no proporciona una actividad comercial al uso como las que acabamos de indicar. Para un análisis más en profundidad al respecto, se recomienda A. Pensado Seijas (2015), «Regulación jurídica actual de las antenas de telefonía móvil: de la Ley 33/2003, de 3 de noviembre, a la Ley 9/2014, de 9 de mayo, General de Telecomunicaciones», Revista Jurídica de Castilla y León, 36, págs. 1-45.

18 Véase la Sentencia de la Audiencia Nacional de 1 de septiembre de 2011, fundamento jurídico $3^{\circ}$. 
Pues bien, una vez presentada esa comunicación/declaración responsable en el Registro General de la Administración local en cuyo término se va a ejercer la actividad o en cualquiera de los registros descritos en el art. 16.4 de la LPACAP, conviene preguntarnos si se inicia un procedimiento administrativo o si debe seguirse una concreta tramitación al respecto. El art. 69.3 de la misma LPACAP establece que, con carácter general, se permite el ejercicio del derecho (realización de la obra...) o el inicio de la actividad, según los casos, «desde el mismo día de su presentación, sin perjuicio de las facultades de comprobación, control e inspección que tengan atribuidas las Administraciones Públicas» ${ }^{19}$.

En otras palabras, la presentación de una comunicación/declaración responsable conlleva cuatro consecuencias. Por un lado, antes de que la actividad/obra efectivamente se inicie, la Administración no tiene potestad para admitirla, sino que tendrá un comportamiento silente, siguiendo a la doctrina italiana ${ }^{20}$. Por otro lado, no hay una resolución administrativa puesto que hemos dicho que no debe haber aceptación expresa por parte de la Administración pública ${ }^{21}$. A su vez, no se precisa ningún acto ni certificado

19 En este mismo sentido se expresa el art. 5 de la LMULCDS.

20

Para un análisis más profundo, recomiendo a M. Rodríguez Font (2009), «Declaración responsable y comunicación previa: su operatividad en el ámbito local», Anuario del Gobierno Local, 1, págs. 261-300 (pág. 278). De acuerdo con la cual: «La Administración no ha tenido potestad para consentir la actividad; y su potestad para vetarla se ha encontrado, en principio, limitada en el tiempo. Sólo se ha manifestado de forma expresa, a través de un acto administrativo, cuando previa comprobación ha decidido prohibir su ejercicio por no ser conforme a Derecho. Si no ha hallado motivos para oponerse, ha permanecido en "silencio"; silencio que en palabras de la doctrina italiana no tiene ningún valor, ni positivo ni negativo, tratándose simplemente de "un comportamiento silente". La clave para entender si esta modalidad de comunicación tiene entrada en la definición comunitaria de autorización reside, precisamente, en el valor que se otorgue a este "comportamiento"".

21 Si bien se trata de distinta materia, podemos traer aquí a colación la crítica que realiza el Consejo de Estado en su dictamen 1.827/2009, de 10 de diciembre de 2009, relativo al proyecto de Real Decreto por el que se modifica el Real Decreto 1199/1999, de 9 de julio, por el que se desarrolla la Ley 13/1998, de 4 de mayo, de ordenación del Mercado de Tabacos y normativa tributaria y se regula el Estatuto Concesional de la Red de Expendedurías de Tabaco y Timbre (apdo. 2o.V.c): «[...] llama la atención a este Consejo que se emplee en este contexto el verbo "aprobar"; y ello porque, en principio y de conformidad con las reflexiones anteriores, la declaración responsable no tiene que ser objeto de aprobación alguna para producir efectos: basta la mera presentación de este documento para que el interesado pueda comenzar a desempeñar la actividad a que se refiere la declaración. Y ello — hay que insistir — sin perjuicio de la 
administrativo ${ }^{22}$; otra cuestión distinta es que algunas administraciones hayan optado por utilizar fórmulas de "toma de razón" ${ }^{23}$, las cuales, en esencia, no constituyen auténticos actos administrativos; es más, en este punto, la doctrina destaca que las comunicaciones/declaraciones responsables son actos de particulares. Por último, no se puede retrasar el inicio de esa actuación del particular, por ejemplo, solicitando la inscripción en un determinado registro.

Lo aquí afirmado no es óbice para tramitar un determinado expediente, ni para que la Administración ejercite sus posibilidades de comprobación, control e inspección, pero siempre siguiendo el principio pro libertatis ${ }^{24}$. De hecho, ya en 2010 autores como González García defendían que «es la norma donde se ha de configurar un procedimiento adaptado a la naturaleza de estas comunicaciones previas, el cual tiene que partir del hecho de la tramitación

posibilidad de que la eficacia de la declaración pueda en hipótesis quedar condicionada en determinados supuestos a la verificación de ciertos requisitos - lo que no parece suceder en este caso, ya que no se dice expresamente.

En definitiva, la exigencia de que la declaración sea objeto de aprobación podría acercar el régimen de declaración responsable al de autorización o licencia que pretende eliminarse. Con ello el proyecto parece apartarse de los objetivos de simplificación administrativa y eliminación de cargas que persiguen la Directiva de Servicios y sus leyes de transposición, pues en lugar de introducir un procedimiento más sencillo y que facilite el inicio de la actividad, crea un peculiar régimen de intervención administrativa en el que declaración, comprobación y aprobación dan lugar a un complejo sistema de acceso al servicio que se compadece mal con la agilidad que, en principio, caracteriza al régimen de declaración responsable.

Las consideraciones anteriores llevan a este Consejo a sugerir que se replanteen los términos en que el proyecto regula el régimen de declaración responsable, a fin de despejar las dudas que este sistema plantea en su actual redacción y que han quedado apuntadas. Y, en todo caso, debe eliminarse la exigencia de aprobación que, en su caso, podría sustituirse por una referencia a la posibilidad de que el presidente del Comisionado dicte resolución por la que reconozca expresamente la habilitación al interesado para desarrollar su actividad (aun cuando, en rigor, tal resolución no sea necesaria en un régimen de declaración)».

22 Más aún, siguiendo a Rodríguez Font, la Administración «sólo se ha manifestado de forma expresa, a través de un acto administrativo, cuando previa comprobación ha decidido prohibir su ejercicio por no ser conforme a Derecho» (2009: 278).

23 Parece seguir también esta teoría J. R. Fernández Torres, «Regímenes de intervención administrativa: autorización, comunicación previa y declaración responsable», Revista catalana de dret públic, 42, págs. 85-114 (págs. 103 y 104).

24 F. A. Cholbi Cachá (2010), El régimen de la comunicación previa, las licencias de urbanismo y su procedimiento de otorgamiento, Madrid: La Ley Actualidad (pág. 76). 
electrónica del procedimiento, que es la forma que se pretende que se ejercite, ya que debería servir en el marco de toda la Unión Europea, a través del procedimiento de ventanilla única» ${ }^{25}$.

Volviendo a los efectos de la presentación de una comunicación/declaración responsable, hemos dicho que el art. 69.3 de la LPACAP permite, con carácter general, el ejercicio del derecho (realización de la obra...) o el inicio de la actividad, según los casos, "desde el mismo día de su presentación, sin perjuicio de las facultades de comprobación, control e inspección que tengan atribuidas las Administraciones Públicas». En este mismo sentido se expresan un grupo de sentencias del TSJ de Madrid, entre las cuales cabe citar, a modo de ejemplo, la sentencia de la Sección $2^{\text {a }}$ de la Sala de lo ContenciosoAdministrativo del TSJ de Madrid de 2 de abril de 2014. Esta última, en su FJ $5^{\circ}$, tras recordar la definición de declaración responsable y de comunicación previa del art. 71 bis de la Ley 30/1992 de Régimen Jurídico de las Administraciones Públicas y Procedimiento Administrativo Común (LRJPAC) entonces vigente, establece que con la presentación de cualquiera de estos documentos se «producirán los efectos que se determinen en cada caso por la legislación correspondiente y permitirán, con carácter general, el reconocimiento o ejercicio de un derecho o bien el inicio de una actividad, desde el día de su presentación, sin perjuicio de las facultades de comprobación, control e inspección que tengan atribuidas las Administraciones Públicas». Por lo tanto, observamos el sustancial cambio de régimen jurídico respecto al anterior, reconociéndose ahora, con carácter general, un control expost, en lugar de uno a priori o preventivo (existente ante una actuación sometida a licencia).

Todavía más clarificadora resulta la sentencia 126/2014 del Juzgado de lo Contencioso-Administrativo $\mathrm{n}^{\circ} 2$ de Barcelona de 8 de mayo de 2014, cuyo $\mathrm{FJ} 3^{\circ}$ no solo se refiere a los efectos inmediatos antes indicados y a todos aquellos que determine la legislación correspondiente, sino que también reconoce que las declaraciones responsables y comunicaciones previas «no finalizan mediante un acto definitivo que pueda ser objeto de recurso", tal y como habíamos destacado con anterioridad en este mismo epígrafe. Para llegar a esta conclusión, este juzgado se basa en el último párrafo del antes vigente art. 42.1 de la LRJPAC (hoy, 21 de la LPACAP), el cual establece la excepción de dictar resolución expresa en «los procedimientos relativos al ejercicio de derechos sometidos únicamente al deber de comunicación previa a la Administración».

25 J. González García (2010), «Autorizaciones, Comunicaciones Previas y Declaraciones Responsables en la transposición de la Directiva de Servicios», Revista d'studis autonômics i federals, 11, págs. 255-293 (pág. 286). 
Por este motivo, la Sala de lo Contencioso-Administrativo de los TSJ del Principado de Asturias y de Andalucía de Sevilla, en sentencias de 23 de febrero de 2015 y de 10 de octubre de 2013, respectivamente, no consideran viable la aplicación del mecanismo del silencio administrativo en relación con las obras o usos sobre los que se ha realizado una comunicación/declaración responsable, distinguiendo estas de la solicitud de licencia ${ }^{26}$. Hilando con la idea del párrafo anterior, si no existe un plazo para emitir una resolución, difícilmente se puede computar el mismo y, en consecuencia, hablar de silencio administrativo. Por su parte, la sentencia sevillana, en su FJ 6º, no ha aceptado argumentos contrarios a lo afirmado como la vulneración del principio de autonomía local alegada con motivo de sustituir la exigencia de licencia de apertura por estas figuras de la declaración responsable o comunicación; tampoco la idea de vulneración del principio de confianza legítima cuando la orden de clausura la adopta la Administración competente.

\section{POSIBILIDAD DE EXIGENCIA DE TRIBUTOS ANTE LA PRESENTACIÓN DE UNA DECLARACIÓN RESPONSABLE O DE UNA COMUNICACIÓN VINCULADA A UNA ACTIVIDAD COMERCIAL O DE SERVICIO}

Una cuestión relacionada con la anteriormente tratada nos lleva a analizar la posibilidad de que la Administración exija el abono de tributos ante la presentación por parte de un particular de una declaración responsable o de una comunicación vinculada a una obra o a una actividad comercial o de servicio. El apdo. primero del preámbulo de la LMULCDS ha declarado expresamente que "[1]a sustitución de la licencia por otros actos de control ex post no supondrá en ningún caso merma alguna de los ingresos fiscales de los Ayuntamientos o de los organismos que expidieran con anterioridad las licencias previas de apertura. Por el contrario, en la medida que se agilice la apertura de nuevos establecimientos, podrá registrarse un incremento de la recaudación obtenida por este concepto al facilitarse la apertura de más y nuevos comercios. Esta ley modifica el Texto Refundido de la Ley Reguladora de las Haciendas Locales (TRLHL), aprobado por el Real Decreto Legislativo 2/2004, de 5 de marzo, con este fin». Así lo recuerda también el FJ $3^{\circ}$ de la sentencia 285/2014 de la

26 En concreto, hemos citado la Sentencia de la Sala de lo Contencioso-Administrativo de los TSJ del Principado de Asturias de 23 de febrero de 2015. De acuerdo con el segundo párrafo de su $\mathrm{FJ} 3^{\circ}$, «no existiendo solicitud de licencia de ningún género, sino comunicación previa, no considera esta Sala viable la aplicación del mecanismo de silencio administrativo en relación con las licencias de obra previsto en el art. 9.7 del Real Decreto Legislativo 2/2008, de 20 de junio». 
Sala de lo Contencioso-Administrativo, Sección 2a , del TSJ de Castilla y León de Burgos de 22 de diciembre de 2014.

En concreto, y atendiendo a la materia que nos ocupa, podemos plantearnos dos opciones cuya viabilidad analizaremos a continuación: por un lado, la posibilidad de imposición de una tasa por servicios urbanísticos ante la presentación de una comunicación/declaración responsable con motivo del inicio de una actividad comercial o de servicios o ante la realización de una obra de acondicionamiento para ella y, por otro lado, la posible exigencia del Impuesto de Construcciones, Instalaciones y Obras (ICIO) con ocasión de la realización de la misma obra de acondicionamiento de la indicada actividad.

2.1. Posibilidad de imposición de una tasa por servicios urbanísticos ante la presentación de una comunicación/declaración responsable vinculada a una actividad comercial o de servicios

Analizada la jurisprudencia existente, podemos adelantar que actualmente parece superada esta discusión puesto que los tribunales se han mostrado favorables a la posibilidad de que un ayuntamiento imponga una tasa por prestación de servicios urbanísticos ante la presentación de comunicaciones/ declaraciones responsables en sentencias como las de la Sala de lo Contencioso-Administrativo, Sección $2^{a}$, del TSJ de Castilla y León de Burgos de 22 de diciembre de 2014 o la de la Sala $3^{a}$ de lo Contencioso-Administrativo, Sección 2a del Tribunal Supremo 1.558/2016 de 28 de junio de 2016.

Concretamente, la primera de estas resoluciones judiciales ha requerido, con buena lógica, que se encuentre en vigor una ordenanza fiscal que reconozca la posibilidad de su exigibilidad para que la Administración pueda reclamar dicha tasa ante la presentación de este tipo de documentos; de manera que, en caso contrario, ha estimado procedente anular la liquidación practicada considerando que "no concurre el hecho imponible de la tasa girada» prevista para la tramitación de una licencia de apertura cuando se ha exigido la misma ante la presentación de una comunicación previa de inicio de actividad de un parque eólico ${ }^{27}$.

Como se reconoce expresamente, "[...] una cosa es que los Ayuntamientos tengan la posibilidad de establecer tasas por la realización de tales actividades, y otra, que el Ayuntamiento de Ágreda pueda exigir Tasas por un concepto u otro indistintamente, sin la previa aprobación de la oportuna Ordenanza acordando su concreta imposición». Por lo tanto, dicha ordenanza

27 Véase la Sentencia de la Sala de lo Contencioso-Administrativo, Sección 2a ${ }^{a}$, del TSJ de Castilla y León de Burgos, no 285/2014, de 22 de diciembre de 2014, FJ 3º. 
fiscal debe seguir la tramitación exigida por el art. 17 del TRLHL puesto que, en otro caso, incurrirá en nulidad de pleno derecho, tal y como dispone la sentencia de la Sala de lo Contencioso-Administrativo, Sección 1a ${ }^{a}$, del TSJ del Principado de Asturias de 14 de abril de 2014.

Debemos recalcar también, por todo ello, la necesidad de reconocimiento expreso de este supuesto concreto en la ordenanza fiscal puesto que, como también se pronuncia el TSJ de Castilla y León de Burgos en la citada sentencia de 22 de diciembre de 2014, "no cabe invocar la analogía a la hora de aplicar la meritada Tasa, pues el art. 14 de la LGT es claro al respecto, y no admite la analogía para extender más allá de sus términos estrictos el ámbito del hecho imponible, de las exenciones y demás beneficios e incentivos fiscales, debiendo reiterarse que en el presente caso la Ordenanza aplicada es clara».

Respecto a los elementos de este tributo, podemos volver también a la sentencia antes mencionada del Tribunal Supremo de 28 de junio de 2016, la cual ha declarado que hoy el hecho imponible viene constituido por «la actividad técnica y administrativa del Ayuntamiento tendente a verificar los actos de edificación y uso del suelo, sujetos a previa licencia o declaración responsable, para determinar si se ajustan a la normativa sectorial» aplicable ${ }^{28}$ y, añade la doctrina, que también se analizará si se adecúan al planeamiento urbanístico y a las ordenanzas municipales ${ }^{29}$. En el mismo sentido, se expresan las sentencias de los TSJ de la Comunidad Valenciana, Sala de lo Contencioso-Administrativo, Sección 3a , de 9 de abril de 2013 (FJ 2º) y de Andalucía de Granada, Sección 2a, de 25 de enero de 2016 (FJ 2º).

En consecuencia, los órganos judiciales han concluido que se produce una actividad administrativa que afecta de modo particular al sujeto pasivo, al hilo del art. 20.1 TRLHL. Es indiferente en ese primer punto que se emita una resolución formal o no puesto que solo se exige actividad administrativa provocada por esa persona interesada, no un acto administrativo ${ }^{30} \mathrm{o}$, incluso, podría darse el caso de que se dictara una resolución desfavorable, habiéndose

28 Hemos citado la Sentencia de la Sala $3^{\text {a }}$ de lo Contencioso-Administrativo, Sección $2^{a}$, del Tribunal Supremo no 1.558/2016 de 28 de junio de 2016, FJ $3^{\circ}$.

29 En este punto recomiendo M. del M. Pérez Pérez (2010), «La nueva tasa por la actuación de control posterior de aperturas de establecimientos sometidas al procedimiento de Comunicación Previa y Declaración Responsable», El Consultor de los Ayuntamientos, 8, págs. 1309-1319 (pág. 1314).

30 Siguiendo otras sentencias, como la del Tribunal Supremo de 5 de febrero de 2010, la sentencia del TSJ de Cataluña, Sala de lo Contencioso-Administrativo, Sección $1^{\mathrm{a}}, \mathrm{n}^{\mathrm{o}}$ 842/2013 de 9 de septiembre de 2013, analiza en detalle esta idea. Un ejemplo de este abono de tasas sin actuación administrativa es el otorgamiento de licencia por silencio administrativo $\left(\mathrm{FJ} \mathrm{3} 3^{\circ}\right.$. 
superado en ese punto el criterio del Tribunal Supremo expresado en sentencia de 19 de enero de 2000. El motivo, como defiende la última sentencia del TSJ citada, reside en que no estamos ante un tributo de resultado.

Ahora bien, existen límites. Así, el Tribunal Supremo había aclarado en una sentencia anterior, de 13 de octubre de 1992, que levantar un acta de inspección no constituye fundamento jurídico para el cobro de esta tasa puesto que se enmarca dentro del servicio de policía que se presta con carácter general por el Ayuntamiento para asegurar el mantenimiento de la actividad dentro de los límites preceptivos. Este órgano judicial no considera la inspección general como una actuación de la verificación de que lo presentado cumple con la normativa reguladora (que supondría el objeto de la tasa por prestación de servicios urbanísticos) $)^{31}$.

Por su parte, la antedicha sentencia del Tribunal Supremo de 28 de junio de 2016 también ha precisado, en su FJ $3^{\circ}$, que no puede equipararse el coste de la actividad municipal de otorgamiento de una licencia al de la mera presentación de una comunicación/declaración responsable. Este órgano judicial considera que, si la base es simplificar la actividad administrativa con un control ex post, sería incoherente sostener y mantener que con las técnicas de este tipo de control la actividad administrativa a desarrollar es la misma que en el caso de un control preventivo. En otras palabras, se precisa que «la actuación administrativa para comprobar que un determinado proyecto cumple las exigencias legales para su desarrollo no es igual si requiere el examen previo de instalaciones y proyectos que si de lo que se trata es de confrontar que unos y otras se han implantado y se desarrollan con arreglo al ordenamiento jurídico».

En concreto, el tema del coste económico de la actuación administrativa que se realiza es relevante para la exigencia de tasas puesto que, como establece el art. 24.2 del TRLHL:

[...] el importe de las tasas por la prestación de un servicio o por la realización de una actividad no podrá exceder, en su conjunto, del coste real o previsible del servicio o actividad de que se trate o, en su defecto, del valor de la prestación recibida. Para la determinación de dicho importe se tomarán en consideración los costes directos e indirectos, inclusive los de carácter financiero, amortización del inmovilizado y, en su caso, los necesarios para garantizar el mantenimiento y un desarrollo razonable del servicio o actividad por cuya prestación o realización se exige la tasa, todo ello con independencia del presupuesto u organismo que

31 Siguiendo esta misma Sentencia del TSJ de Andalucía de Granada de 25 de enero de 2016, FJ 2º, antes citada, no cabrá la exigencia de tasas cuando la prestación «se desvincula totalmente de una actuación administrativa concreta e individualizada». 
lo satisfaga. El mantenimiento y desarrollo razonable del servicio o actividad de que se trate se calculará con arreglo al presupuesto y proyecto aprobados por el órgano competente.

Atendiendo a lo afirmado, supongamos que exista informe económicofinanciero relativo a dicha tasa ${ }^{32}$, pero que, tras aplicar el porcentaje de la misma, el sujeto pasivo alegue que esa cuantía supera el gasto de los servicios municipales para la actividad de estudio precisa para la determinación de la adecuación o inadecuación a la normativa de ese proyecto. En ese supuesto, siguiendo el mencionado art. 24.2 del TRLHL, se debería anular la liquidación tributaria municipal en su totalidad, tal y como concluyó la sentencia del TSJ de Canarias de Las Palmas de Gran Canaria, Sala de lo ContenciosoAdministrativo, Sección 1a, de 17 de abril de 2015; de manera que esa última resolución, por su parte, reconoció también el derecho del Ayuntamiento de Pájara a girar una nueva liquidación de la tasa por la obra realmente ejecutada. Se busca con todo ello el mantenimiento de «un servicio público concreto y

32 Recordemos aquí que este informe técnico-económico viene requerido por el art. 25 del TRLHL, siendo considerado por la jurisprudencia como una garantía de que la tasa establecida no supera el coste efectivo del servicio administrativo. Así lo reconocen, entre otras, las sentencias de las Salas de lo Contencioso-Administrativo del TSJ de Castilla y León de Burgos de 25 de febrero de 2015 o la sentencia del Tribunal Supremo de 24 de febrero de 2014; de manera que la jurisprudencia llama a este principio de equivalencia o de autofinanciación de las tasas.

Incluso debemos exigir dicho informe también en el caso de modificación de la tasa, siguiendo la antedicha sentencia del TSJ de Castilla y León de Burgos de 25 de febrero de 2015, que considera lo contrario vicio de inmotivación. Las únicas excepciones a lo afirmado son las reconocidas expresamente en la normativa de Haciendas locales: revalorizaciones o actualizaciones de carácter general y supuestos de disminución del importe de la tasa (con una excepción de la excepción en este último: que esa reducción del coste del servicio sea sustancial puesto que, en esos casos, como concluye el Tribunal Supremo en sentencia de 27 de noviembre de 2012, se afectaría «esencialmente al montante de la tarifa»).

Por su parte, en caso de inexistencia del mismo, se ha anulado también la liquidación de la tasa, tal y como ha concluido el Tribunal Supremo en la meritada sentencia de 28 de junio de 2016, FJ 30. Pero para ello debe acreditarse por la actora de manera indubitada que el contenido del informe es insuficiente, en qué medida no sirve para conocer el coste de la actividad o del servicio o, incluso, que la tasa exigida es superior al coste del servicio «en términos tales que se ha vulnerado clara y tajantemente el principio de equivalencia» y la naturaleza de las tasas puesto que, en caso contrario, no se anulará la liquidación recurrida, tal y como justifica la aquí citada sentencia del TSJ de Castilla y León de Burgos de 25 de febrero de 2015, en su FJ 7º. 
bien determinado, tal y como se infiere del artículo 24.2 LHL [...] sin que el régimen constitucional y legal vigente permita la imposición de verdaderos impuestos indirectos sobre el uso de los servicios o actividades públicas (SSTS de 11 de junio de 1996 y de 22 de mayo de 1998)»33.

Como afirma el Tribunal Supremo en sentencia de 19 de septiembre de 2013, los indicados límites legales y las exigencias del procedimiento formal de la adopción de los acuerdos municipales y de su publicación serán los únicos puntos examinados por los órganos judiciales cuando se recurra una ordenanza fiscal, puesto que estas suponen el «ejercicio de funciones soberanas o políticas, que tampoco exigen motivación ni razonamiento expreso alguno, al tratarse del ejercicio del poder tributario local, de acuerdo con la jurisprudencia del Tribunal Constitucional y el artículo 9.3 de la Carta de Autonomía Local de 15 de octubre de 1985».

Ahora bien, en el supuesto de que no se realizase la actividad de comprobación administrativa porque antes de ello ese interesado/a renuncia a efectuar la obra o a iniciar la actividad, los tribunales han considerado que ese ingreso de la tasa, que era debido cuando se hizo, ha devenido en indebido finalmente porque el hecho imponible no va a realizarse. Solo a partir de la presentación de la renuncia se consideraría el ingreso como indebido, lo cual es relevante para fijar el cómputo del dies a quo para solicitar dicha devolución así como para el cómputo de intereses ${ }^{34}$.

33 En este punto, hemos citado la Sentencia del TSJ de Cataluña, Sala de lo Contencioso-Administrativo, Sección 1a ${ }^{a}$ no 842/2013, de 9 de septiembre de 2013, en su FJ $3^{\circ}$. Esta resolución judicial exige analizar la actuación administrativa desplegada efectivamente y, en consecuencia, analizar el expediente administrativo incoado tras la presentación de la comunicación/declaración responsable en cuestión con el fin de calcular ese coste; de manera que en este punto concreto me gustaría llamar la atención respecto al posible peligro de eliminar del expediente administrativo algunos de los documentos descritos en el art. 70.4 de la LPACAP (tales como los informes internos o entre órganos de esa Administración local, o los informes preceptivos o facultativos solicitados a otra Administración antes de la resolución administrativa con competencias sectoriales — sería el caso de una Autoridad Portuaria para actividades a desarrollar en puertos de interés general...).

34 En este sentido, existe diversa jurisprudencia menor entre la que cabe citar, por todas, la Sentencia del TSJ, Sala de lo Contencioso-Administrativo, Sección 1a , de la Comunidad Valenciana de 4 de mayo de 2016, en su FJ 6º ahora bien, este tribunal también considera en el FJ 7o que distinta hubiera sido la conclusión si se hubiera solicitado la devolución de la tasa como consecuencia de la no realización de la actuación administrativa por causas imputables a la propia Administración puesto que, en ese caso, procedería la devolución del importe correspondiente siempre, según el art. 26.3 del TRLHL. 
Por otro lado, en cuanto al sujeto pasivo, atendiendo a la definición de hecho imponible facilitada por la normativa, deberá abonar esta tasa la persona a la que afecta o se refiere la actividad administrativa en este caso, siempre que haya sido motivada directa o indirectamente por esta «en razón de que sus actuaciones u omisiones obliguen a las entidades locales a realizar de oficio actividades o a prestar servicios por razones de salubridad, de abastecimiento de la población o de orden urbanístico, o cualesquiera otras». Así lo reconoce la Sentencia del TSJ de Andalucía de Granada, Sala de lo Contencioso-Administrativo, Sección $2^{a}$, de 25 de enero de 2016, en su FJ 2ª, citando al respecto la Sentencia del Tribunal Supremo de 5 de febrero de 2010.

Incluso, la Sentencia del TSJ de Madrid, Sala de lo Contencioso-Administrativo, Sección 9a , de 11 de febrero de 2016, concluye en su FJ $8^{\circ}$ que una empresa concesionaria que realiza una obra de construcción de un polideportivo municipal (para posteriormente gestionarlo) está sujeta a esta tasa si el personal técnico municipal supervisa el proyecto y se realiza una actividad de control por ese ayuntamiento.

A su vez, para saber cuándo se produce el devengo de este tipo de tasas, se estará al momento en que se inicia la actividad municipal tendente a verificar si esos actos se ajustan a la normativa sectorial exigible, siguiendo el derecho tributario clásico; la doctrina lo sitúa en la presentación de la comunicación/ declaración responsable ${ }^{35}$. Así lo han considerado también sentencias, como la ya mencionada del Tribunal Supremo de 28 de junio de 2016, puesto que entienden que en ese momento el Ayuntamiento "comienza a verificar técnica y administrativamente la adecuación del proyecto presentado de acuerdo con la normativa urbanística de aplicación»"; de manera que la "tasa se autoliquida por los sujetos pasivos en el plazo de un mes a partir del momento en que se "estime suficiente la declaración responsable para ejecutar la obra" "37. En otras palabras, no existe cobertura legal para un devengo diferido al momento de terminación de las obras, sino solo para una comprobación de la corrección de la misma en atención al presupuesto presentado con el proyecto ${ }^{38}$.

Ahora bien, en ese último momento deberá tenerse cuidado con la prescripción. A este respecto, la sentencia del TSJ de la Comunidad Valenciana,

35 Véase Pérez Pérez (2010: 1316).

36 La transcripción de esa última coletilla, en concreto, se realiza respecto a la sentencia del TSJ de Andalucía de Granada, Sala de lo Contencioso-Administrativo, Sección 2a, no 166/2016, de 25 de enero de 2016, FJ 20.

37 Sentencia del Tribunal Supremo de 28 de junio de 2016 ya citada, FJ $3^{\circ}$.

38 Fundamentamos dicha idea en la Sentencia del TSJ de la Comunidad Valenciana, Sala de lo Contencioso-Administrativo, Sección 1a, no 899/2016, de 9 de noviembre de 2016. 
Sala de lo Contencioso-Administrativo, Sección 3a, de 9 de abril de 2013, en su FJ 20, fija como dies a quo el de la fecha de la resolución formal que indicaba que se había producido dicha actividad o la presentación de la comunicación del inicio de las actuaciones inspectoras; y como dies ad quem, el de la notificación de la liquidación de la tasa. Esto no obsta para que se pueda exigir un depósito previo de su importe total o parcial, siguiendo lo dispuesto en el art. 26.1.a) del TRLHL.

2.2. Posibilidad de exigencia del ICIO ante la presentación de una comunicación/ declaración responsable relativa a una obra vinculada a una actividad comercial o de servicios

Igual que hemos concluido respecto a la tasa por la prestación de servicios urbanísticos, hoy no se discute la exigibilidad de este impuesto de naturaleza indirecta con motivo de la presentación de una comunicación/ declaración responsable para el inicio de obras vinculadas a una actividad comercial o de servicios.

Sabemos que en este caso el hecho imponible es la realización en ese término municipal de cualquier construcción, instalación u obra para la que se exija o bien obtener licencia o bien presentar la declaración responsable o la comunicación, tal y como reconoce la Sentencia del TSJ de la Comunidad Valenciana, Sala de lo Contencioso-Administrativo, Sección 1 1a, de 9 noviembre de 2016, en su FJ 5º, con base en el art. 100 del TRLHL. Más en concreto, siguiendo la sentencia de la Sala de lo Contencioso-Administrativo del Tribunal Supremo de 14 de septiembre de 2005, el nacimiento de la obligación tributaria (ese presupuesto fáctico que la ley establece y cuya realización tiene como consecuencia el devengo del impuesto) se desarrolla en el lapso de tiempo que media entre el comienzo y la finalización de la obra; de manera que el hecho imponible del ICIO se produce realmente cuando finalizan las obras objeto de esa declaración o comunicación puesto que viene constituido por la realización en ese término municipal de cualquier construcción, instalación u obra $^{39}$ para la que se exija licencia de obras o, en otro caso, la presentación de comunicación/declaración responsable.

La verdadera excepción en este punto son las obras de marcado interés público realizadas por administraciones territoriales supramunicipales, tales

39 La excepción son las declaradas expresamente exentas. Siguiendo el art. 100.2 del TRLHL, este último es el caso de las destinadas «a carreteras, ferrocarriles, puertos, aeropuertos, obras hidráulicas, saneamiento de poblaciones y de sus aguas residuales, aunque su gestión se lleve a cabo por organismos autónomos» y aunque sean obras de mera conservación. 
como autopistas o presas hidráulicas que se integran en la ordenación del territorio y no en la ordenación urbanística y que la jurisprudencia excluye de toda intervención municipal. En este punto conviene citar, para aclarar, la Sentencia del TSJ de Madrid, Sala de lo Contencioso-Administrativo, Sección $9^{a}$, de 11 de febrero de 2016, en cuyo FJ $6^{\circ}$ cita a su vez las sentencias del Tribunal Supremo de 21 de abril de 1997 o de 19 de febrero de 2000, y considera que no tiene este carácter de marcado interés público la obra de construcción de un polideportivo municipal y su aparcamiento anexo.

Como vemos, resulta importante en este punto una inspección municipal que acredite, con presunción iuris tantum, que, al menos, se ha comenzado y realizado parte de la obra proyectada, con una valoración de la misma realizada por personal técnico municipal. Así lo resalta la Sentencia del TSJ de la Región de Murcia, Sala de lo Contencioso-Administrativo, Sección $2^{\mathrm{a}}, \mathrm{n}^{\mathrm{o}}$ 42/2017, de 31 de enero de 2017 en su FJ 3º, la cual, además, exige que sea el sujeto pasivo quien enerve, en su caso, dicha presunción, siendo irrelevante en este punto que la actividad haya comenzado a funcionar puesto que nos estamos refiriendo ahora al ICIO y no a la tasa por la prestación de servicios urbanísticos.

Hemos dicho que el hecho imponible se produce en este caso entre el lapso de tiempo que media entre el comienzo y el fin de las obras; ahora bien, sabemos que, como regla general, la normativa básica no está fijando un plazo máximo para la realización de esas obras declaradas o comunicadas y, sin embargo, resulta lógico también pensar que ese documento presentado por la ciudadanía no tendrá efectos sine die. Con el fin de solucionar este posible problema, se considera conveniente tomar ejemplo de la amplia variedad de ordenanzas locales que sí están introduciendo plazos máximos para la realización de dichas obras; por consiguiente, podría defenderse, igual que en el caso de las licencias, que el plazo de prescripción comenzaría a computar ante una comunicación/declaración responsable también cuando hubiera transcurrido dicho plazo máximo para terminar las obras vinculadas a esa actividad comercial o de servicios.

Lo mismo sucedería si se renuncia a la realización de esas obras, pero se hubiera comenzado con ellas, tal y como prevé la Sentencia del TSJ de Castilla y León de Valladolid, Sala de lo Contencioso-Adminisrativo, Sección 3a, de 10 de diciembre de 2013, en su FJ 30 , incluso, aunque la Administración no hubiera adoptado resolución expresa relativa a dicha renuncia ${ }^{40}$. Es más, si se

40 A este respecto, la Sentencia del TSJ de Canarias de Las Palmas de Gran Canaria, Sala de lo Contencioso-Administrativo, Sección 1a de 17 de abril de 2015, en su FJ $4^{\circ}$ considera que el silencio administrativo es positivo en el caso de la presentación de renuncia a la obra; de manera que la prescripción de cuatro años para solicitar la de- 
presenta una renuncia a la obra y no se ha iniciado la misma, igual que hemos explicado con las tasas, los tribunales han considerado que ese ingreso que era debido cuando se hizo ha devenido en "indebido" finalmente porque el hecho imponible no va a realizarse; solo a partir de la presentación de la renuncia se considerará el ingreso como indebido, lo cual es relevante para fijar el cómputo del dies a quo para solicitar dicha devolución así como para el cómputo de intereses. En este último sentido, existe diversa jurisprudencia menor entre la que cabe citar las sentencias de los TSJ del País Vasco de 21 de septiembre de 2012, de Andalucía de Granada de 22 de febrero de 2016 en su FJ 30 o el de la Comunidad Valenciana de 4 de mayo de 2016 en su FJ 5o, entre otras resoluciones. Ahora bien, cabe aclarar, siguiendo el FJ $7^{\circ}$ de esta última sentencia de 4 de mayo de 2016, que la conclusión habría sido distinta si no se hubiese realizado la obra como consecuencia de un incumplimiento de la Administración puesto que, en ese supuesto, se ha considerado la existencia de responsabilidad patrimonial y la correspondiente indemnización de intereses.

Llegados a este punto, conviene preguntarnos qué sucedería si no hubiéramos adaptado la ordenanza fiscal a la normativa actualmente vigente y si estuviéramos ante una obra ahora sujeta a declaración responsable o a comunicación. Si bien los órganos judiciales no se han pronunciado en este punto a día de hoy, la doctrina mayoritaria sigue a los magistrados del TSJ de Cataluña Galindo Morell y Aragonés Beltrán, quienes defienden una interpretación teleológica o hermenéutica del artículo 100.1 del TRLHL para considerar sujeta al ICIO toda obra, fuera cual fuese su régimen de intervención administrativa ${ }^{41}$.

Atendiendo a estas precisiones realizadas, sentencias como la del TSJ de Canarias de Las Palmas de Gran Canaria, Sala de lo Contencioso-Administrativo, Sección 1a , de 17 de abril de 2015 o de 13 de septiembre de 2016, consideran que la liquidación que se gira cuando se presenta este documento por la ciudadanía es una liquidación provisional o, en otras palabras, un simple pago

volución del ICIO comenzaría en ese caso «desde el día siguiente a aquel en que dicha devolución pudo solicitarse» (caducidad de la licencia de obras o fecha de la renuncia). M. del M. Pérez Pérez (2012), «La incidencia de la Directiva de Servicios en la fiscalidad municipal», en M. J. Fernández Pavés (coord.), La función tributaria local (págs. 496-533), Madrid: Editorial El Consultor de los Ayuntamientos y Juzgados.

En ese mismo capítulo, pero citando a Galindo Morell, se recomienda incorporar a la ordenanza fiscal una disposición transitoria con la posible siguiente redacción: «Si se modificase el alcance jurídico de las licencias de obras o urbanísticas de competencia municipal, esta Ordenanza también será aplicable a todas las construcciones, instalaciones y obras que pasen del régimen de intervención al de comunicación previa o al de declaración responsable». 
a cuenta de la liquidación que debe aprobar la Administración local necesariamente, una vez terminadas las obras, a la vista de la liquidación definitiva de estas (FJ $1^{\circ}$ de la primera sentencia aquí citada) o a la vista de la oportuna comprobación administrativa al respecto (FJ $2^{\circ}$ de la misma ${ }^{42}$ ).

Por ello, el FJ $5^{\circ}$ de la Sentencia del TSJ de la Comunidad Valenciana, Sala de lo Contencioso-Administrativo, Sección $1^{\text {a }}$, de 9 de noviembre de 2016, concluye que se distinguen dos fases en la liquidación, al contrario que sucedía en la tasa por la prestación de servicios urbanísticos. Así, a tenor del art. 103.1 del TRLHL, se plantea primero una liquidación provisional cuando se presente la comunicación/declaración responsable o bien cuando, no habiéndose presentado estos documentos, se inicie la construcción, instalación u obra y, en segundo lugar, una liquidación definitiva cuando finalice dicha obra o instalación y se ejecute la comprobación administrativa (bien exigiéndole la cantidad que corresponda o bien reintegrándosela al sujeto pasivo, según corresponde en cada caso).

Por su parte, conviene citar la Sentencia del TSJ de la Región de Murcia, Sala de lo Contencioso-Administrativo, Sección 2a, no 42/2017, de 31 de enero de 2017, de acuerdo con la cual se habilitaría a la Administración para realizar una única liquidación por una empresa que ejecute numerosas obras, en lugar de una por cada obra que realice simultáneamente. En opinión del citado tribunal (FJ $4^{\circ}$ ), este hecho no conlleva que el Ayuntamiento haya prescindido total y absolutamente del procedimiento legalmente establecido, ni ha causado ninguna indefensión al sujeto pasivo.

Con objeto de facilitar la gestión del impuesto, el art. 102.4 del TRLHL determina que el devengo se produce en el momento de iniciarse efectivamente la construcción, instalación u obra, lo cual es interpretado favorablemente por diversas sentencias de la Sala de lo Contencioso-Administrativo del Tribunal Supremo, como las de 28 de julio de 1999, 25 de junio de 2002 o de 14 de septiembre de 2005, la última de las cuales lo califica de «devengo adelantado», «ingreso a cuenta» $\mathrm{o}$ "adelantamiento de pago», al considerar que el devengo media hasta la total finalización de la obra. En el mismo sentido, nos remitiremos también al FJ $2^{\circ}$ de la Sentencia del TSJ de Canarias de las Palmas de Gran Canaria, Sala de lo Contencioso-Administrativo, Sección 1a, de 13 de septiembre de 2016.

Lo hasta aquí referido nos lleva a otra posible cuestión: la prescripción del ICIO. Siguiendo jurisprudencia pacífica, se considera que esta prescripción comienza a contarse "desde aquel momento en el que se sabe que ya no se puede realizar la construcción de las obras gravadas». Ya hemos hablado

42 En el mismo sentido se expresa el art. 103.1 del TRLHL. 
en ese sentido de que comienza a contarse el plazo de prescripción desde el momento en que transcurra el periodo máximo para poder realizar la obra, construcción o instalación. Pues bien, en otros supuestos, esa imposibilidad de realizar la construcción, instalación u obra se entiende, por ejemplo, cuando caduca la comunicación/declaración responsable ${ }^{43}$, sin necesidad de que la Administración local realice declaración formal al respecto. Incluso la Sala de lo Contencioso-Administrativo del TSJ de Castilla-León de Burgos, en sentencia de 25 de abril de 2014, califica de irrelevante en ese punto que las obras se hayan iniciado, pues el comienzo de las mismas «justifica el pago adelantado del impuesto pero sin que ello suponga la realización del hecho imponible».

\section{CONCLUSIÓN}

Las comunicaciones y declaraciones responsables, entendidas como mecanismos ordinarios de intervención de la Administración en la actividad de la ciudadanía, y provenientes de la Directiva 2006/123/CE, están empezando a ocupar su lugar en la jurisprudencia más reciente. Así, a lo largo de este artículo hemos podido concluir, siguiendo diversas resoluciones judiciales, la necesidad de que estos documentos sean presentados tanto por sujetos privados que vayan a realizar una obra o actividad sujeta a dichas figuras, como por una Administración pública con el mismo objetivo; de manera que desde el día de su presentación se podrá comenzar a ejercer la actuación deseada, sin necesidad de acto administrativo alguno. También supondrá su presentación el comienzo del control ex post de esa Administración ante la que se presente, sin perjuicio de que obviamente esta misma pueda inspeccionar actividades para las que no se ha presentado comunicación o declaración responsable alguna y, en su caso, requerir la legalización de las obras realizadas que hubieran precisado la presentación de este tipo de documentos...

43 Entre las sentencias relevantes a este respecto podríamos citar la STS de 14 de septiembre de 2005 o la STSJ de Andalucía de Sevilla, Sala de lo Contencioso-Administrativo, Sección $3^{\text {a }}$, de 22 de julio de 2014. Asimismo, siguiendo sentencias como la del último órgano judicial aquí citado de 5 de mayo de 2006, la persona interesada tiene un plazo de cuatro años a contar desde el día en que abonó el ICIO para reclamar su devolución como ingreso indebido; especialmente relevante en cuanto a su argumentación resulta en este punto la sentencia del mismo TSJ de 30 de julio de 2004, como también la del TS de 17 de diciembre de 2012 que debate entre «ingresos indebidos» e «ingresos debidos que, posteriormente por razón de la técnica impositiva, devienen improcedentes». 
Por otro lado, una vez presentada alguna de estas figuras ante la Administración, no se niega la posibilidad de exigir la tasa por la prestación de servicios urbanísticos siempre que se desarrolle una actividad administrativa concreta de control, análisis de documentación, etc., y, en el supuesto de realizarse obras, incluso, el Impuesto de Construcciones, Instalaciones y Obras (ICIO), siempre cumpliendo con los requisitos previos de ordenanza fiscal con su correspondiente tramitación y documentación anexa, tal y como hemos analizado en el último epígrafe de este artículo. En el caso concreto de la tasa por prestación de servicios urbanísticos, analizada ante este tipo de supuestos concretos, estaremos a la actividad administrativa específica que desarrolle esa entidad local determinada ante la que se haya presentado la declaración responsable o la comunicación, de cara a la cuantía económica de la indicada tasa.

\section{Agradecimientos}

Mi agradecimiento a mi directora de tesis, Maite Uriarte Ricote, por su ayuda en todo momento; así como a la Asociación de Letrados de las Entidades Locales por su invitación a la Jornada sobre Tributos Locales, organizada el 9 de junio de 2017 en Bilbao, en el Colegio de la Abogacía de Bizkaia, puesto que mi exposición en dicho acto ha motivado el presente trabajo. 
